\title{
Thermoresistive properties of p-type 3C-SiC nanoscale thin films for high-temperature MEMS thermal-based sensors $\dagger$
}

\author{
Toan Dinh, ${ }^{* a, \dagger}$ Hoang-Phuong Phan, ${ }^{a, \dagger}$ Takahiro Kozeki, ${ }^{b}$ Afzaal Qamar, ${ }^{a}$ Takahiro Namazu, ${ }^{b}$ Nam- \\ Trung Nguyen, ${ }^{a}$ and Dzung Viet Dao ${ }^{a, c}$
}

Received $* 2015$

DOI: 10.1039/b000000x

We report for the first time the thermoresistive property of p-type single crystalline $3 \mathrm{C}-\mathrm{SiC}$ (p-3C-SiC), which was epitaxially grown on a silicon ( $\mathrm{Si})$ wafer, and then transferred to a glass substrate using a Focused Ion Beam (FIB) technique. A negative and relatively large temperature coefficient of resistance (TCR) up to $\mathbf{- 5 5 0 0} \mathbf{~ p p m} / \mathrm{K}$ was observed. This TCR is attributed to two activation energy thresholds of $45 \mathrm{meV}$ and $52 \mathrm{meV}$, corresponding to temperatures below and above $450 \mathrm{~K}$, respectively, and a small reduction of hole mobility with increasing temperature. The large TCR indicates the suitability of $\mathrm{p}-3 \mathrm{C}-\mathrm{SiC}$ for thermal-based sensors working in high-temperature environments.

In recent years, silicon carbide ( $\mathrm{SiC}$ ) has emerged as an appropriate material for high-temperature electronics thanks to its superior properties, such as large band gap and high thermal conductivity ${ }^{1-4}$. To date, more than $200 \mathrm{SiC}$ polytypes such as $3 \mathrm{C}, 4 \mathrm{H}$ and $6 \mathrm{H}$ have been discovered ${ }^{5,6}$. Among these polytypes, single crystalline $3 \mathrm{C}-\mathrm{SiC}$, with its capability of being grown on a large-diameter silicon (Si) wafer (e.g. 300 $\mathrm{mm})$, is one of the main technological polytypes ${ }^{7-9}$. Thanks to its high temperature coefficient of resistance (TCR) ${ }^{10}$, large band gap ${ }^{11}$ and fast thermal response ${ }^{12}, 3 \mathrm{C}-\mathrm{SiC}$ would be a good material for developing thermal sensors such as temperature sensors $^{13,14}$, flow sensors ${ }^{15-17}$, inertial sensors ${ }^{18,19}$ and micro-heaters 10,20 . In addition, the operation of thermal-based sensors (e.g. thermal flow sensors and convective accelerometers) relies on the Joule heating effect, which requires a low resistivity for small supply voltage and ease of detection. Consequently, crystalline $\mathrm{SiC}$ is a suitable choice for such applications. This material can also be employed for thermal-based sensors integrated with on-chip electronic devices. Further-

* Email of corresponding author: toan.dinh@griffithuni.edu.au

${ }^{a}$ Queensland Micro- and Nanotechnology Centre, Griffith University, Brisbane Queensland 4111, Australia.

${ }^{b}$ Department of Mechanical Engineering, University of Hyogo, Hyogo, Japan.

${ }^{c}$ School of Engineering, Griffith University, Queensland, Australia.

$\dagger$ Toan Dinh and Hoang-Phuong Phan contributed equally to this work.

$\dagger$ Electronic Supplementary Information (ESI) available: The fabrication processes, experimental setup for thermoresistive characterization, the current flow in $\mathrm{p}-3 \mathrm{C}-\mathrm{SiC}$ on $\mathrm{Si}$, and the impact of thermoelectric effect. See DOI: $10.1039 / \mathrm{c} 000000 \mathrm{x} /$ more, the low substrate conductivity is a crucial property for the operation of such SiC thermal sensors ${ }^{10,21}$. However, both the vertical current leakage and the degrading electrical property of the silicon $(\mathrm{Si})$ substrate at high temperatures limit the applications of 3C-SiC on $\mathrm{Si}$ platforms for high-temperature electronic devices ${ }^{22,23}$. A solution for this problem is transferring $\mathrm{SiC}$ onto an insulating substrate. Characterizing the thermoresistive property of the transferred $\mathrm{SiC}$ film is of great interest for practical applications.

Since single crystalline 3C-SiC cannot be grown on any insulating substrates, recent research has focused on transferring techniques such as Smart $\mathrm{Cut}^{24}$ and wafer bonding ${ }^{25}$, to create high-quality single crystalline $3 \mathrm{C}-\mathrm{SiC}$ thin films on insulating substrates. However, these techniques suffer several disadvantages such as implantation damage and a limitation of the implanted oxide layer thickness.
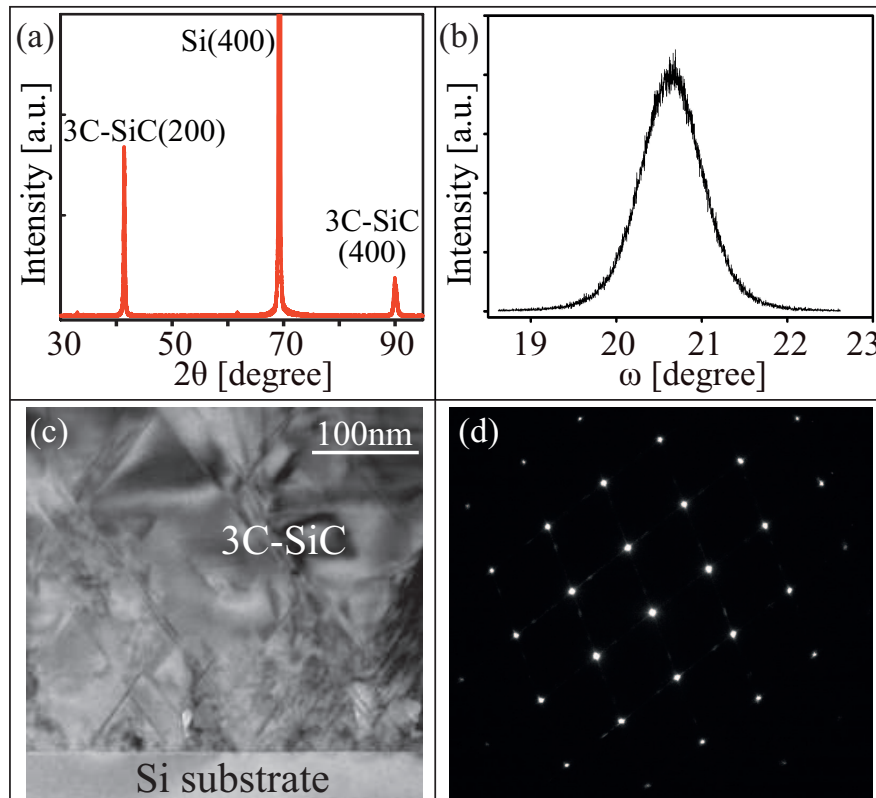

Fig. 1 Characteristics of the SiC film: (a) The XRD graph of p-3C-SiC grown on (100) Si; (b) The rocking curve scan of 3C-SiC; (c) The TEM image of 3C-SiC; (d) The SAED image of 3C-SiC. (Reproduced with permission from ref. 26. Copyright [2014], AIP Publishing LLC.) 
In this paper, we report the growth of the p-3C-SiC on $\mathrm{Si}$ wafer by Low-Pressure Chemical Vapour Deposition (LPCVD) and the subsequent transfer of the $\mathrm{SiC}$ thin film to a glass substrate using the Focused Ion Beam (FIB) technique. We characterized the thermoresistive properties of this material and observed a relatively high temperature coefficient of resistance (TCR). We also demonstrated the use of p-3C-SiC on $\mathrm{SiO}_{2}$ as a suitable material system for high-temperature thermal-based sensors.

The LPCVD process was performed at a temperature of $1273 \mathrm{~K}$ to grow p-3C-SiC nanoscale thin films with a thickness of $280 \mathrm{~nm}$ on (100) $\mathrm{Si}$ substrate. Silane $\left(\mathrm{SiH}_{4}\right)$ and propylene $\left(\mathrm{C}_{3} \mathrm{H}_{6}\right)$ were employed as alternating precursors. To form p-type $\mathrm{SiC}$ material, the trimethylaluminum $\left[\left(\mathrm{CH}_{3}\right)_{3} \mathrm{Al}\right.$, TMAl] precursor was exploited in the in situ doping process. Figure 1(a) shows the full-range of X-Ray Diffraction (XRD) measurement, indicating the growth of $3 \mathrm{C}-\mathrm{SiC}$ on $\mathrm{Si}$. The full width at haft maximum (FWHM) of approximately 0.8 de-

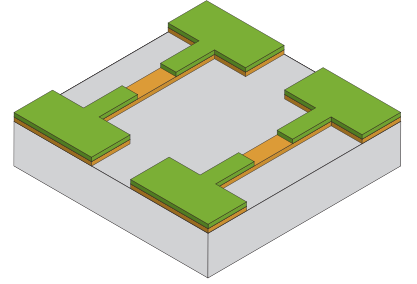

(a) Fabricating $\mathrm{SiC}$ resistors on $\mathrm{Si}$

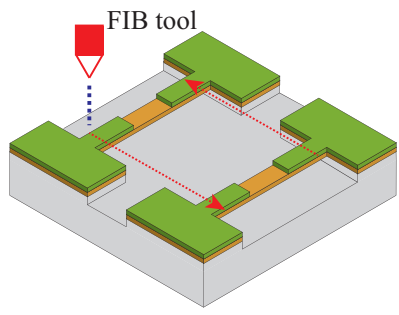

(c) Cutting the $\mathrm{SiC}$ resistors

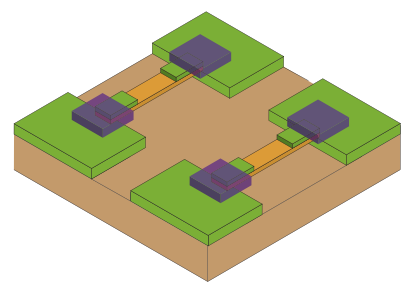

(e) Deposition of tungsten (W)

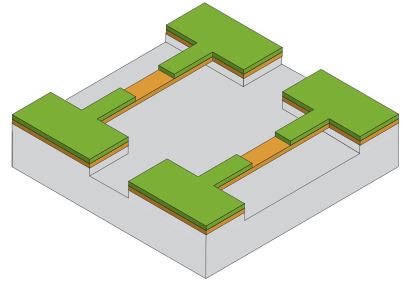

(b) Releasing the $\mathrm{SiC}$ resistors

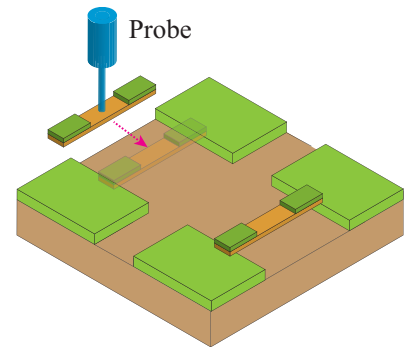

(d) Transferring the $\mathrm{SiC}$ resistors

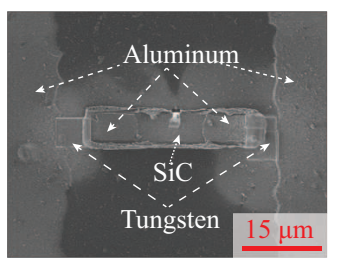

(f) SEM image

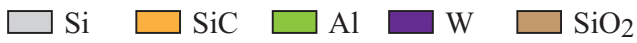

Fig. 2 Fabrication steps of p-3C-SiC on $\mathrm{SiO}_{2}$ : (a) Fabrication of p-3C-SiC on Si substrates; (b) Releasing the $\mathrm{SiC}$ structures; (c) Cutting the $\mathrm{SiC}$ resistors using a Focused Ion Beam (FIB) method; (d) Transferring the $\mathrm{SiC}$ onto a $\mathrm{SiO}_{2}$ substrate; (e) Deposition of tungsten (W); (f) Scanning Electron Microscopy (SEM) image of p-3C-SiC on $\mathrm{SiO}_{2}$. gree was observed (Fig. 1(b)). Furthermore, the Transmission Electron Microscope (TEM) image (Fig. 1(c)) indicates good crystallinity of the as-grown $\mathrm{SiC}$ film. In addition, the selected area electron diffraction (SAED) (Fig. 1(d)) confirms the single crystalline characteristics of the as-grown $\mathrm{SiC}$ film.

The Hall measurement was also performed to determine the carrier concentration of the films at room temperature $(\sim$ $300 \mathrm{~K}$ ). The obtained results indicate a carrier concentration of $5 \times 10^{18} \mathrm{~cm}^{-3}$ for the as-grown $\mathrm{SiC}$ films. In addition, the resistivity of the p-3C-SiC films was measured to be approximately $0.14 \Omega \mathrm{cm}^{-1}$. This resistivity is in the common range used for thermal-based sensors ${ }^{10}$. We also investigated the current flow in $\mathrm{p}-3 \mathrm{C}-\mathrm{SiC}$ on a $\mathrm{Si}$ substrate as a reference $(\mathrm{ESI} \dagger)$. The results indicate that $\mathrm{p}-3 \mathrm{C}-\mathrm{SiC}$ on a $\mathrm{Si}$ substrate is not a good choice for thermal-based sensors at temperatures higher than $350 \mathrm{~K}$. Therefore, we transferred the $\mathrm{p}-3 \mathrm{C}-\mathrm{SiC}$ onto $\mathrm{SiO}_{2}$ and then examined its thermoresistive property for a temperature range of 300 to $600 \mathrm{~K}$, which will be presented hereafter.

We formed the I-shaped $\mathrm{SiC}$ resistors on the Si substrate using standard photolithography and dry etching processes ${ }^{28,29}$ (ESI $\dagger$ ), Fig. 2(a). Aluminum electrodes were used for making the Ohmic contacts between the $\mathrm{SiC}$ films and the subsequent deposited tungsten. We then released the $\mathrm{SiC}$ resistors from the substrate, employing an isotropic dry etching process with $\mathrm{XeF}_{2}$ as the etching gas ${ }^{30}$ (ESI $\dagger$ ), Fig. 2(b). Next, we utilized FIB to remove the $\mathrm{SiC}$ films from the Si substrate, Fig. 2(c). A micro probe $(\mathrm{ESI} \dagger)$ was then employed to transfer the $\mathrm{SiC}$ resistors onto a $\mathrm{SiO}_{2}$ substrate where aluminum electrodes were readily deposited, Fig. 2(d). Finally, a tungsten layer was deposited to fix the $\mathrm{SiC}$ films on the $\mathrm{SiO}_{2}$ substrate, Fig. 2(e). Figure 2(f) shows a scanning electron microscope (SEM) image of a $\mathrm{SiC}$ resistor after it was transferred to the insulating substrate.

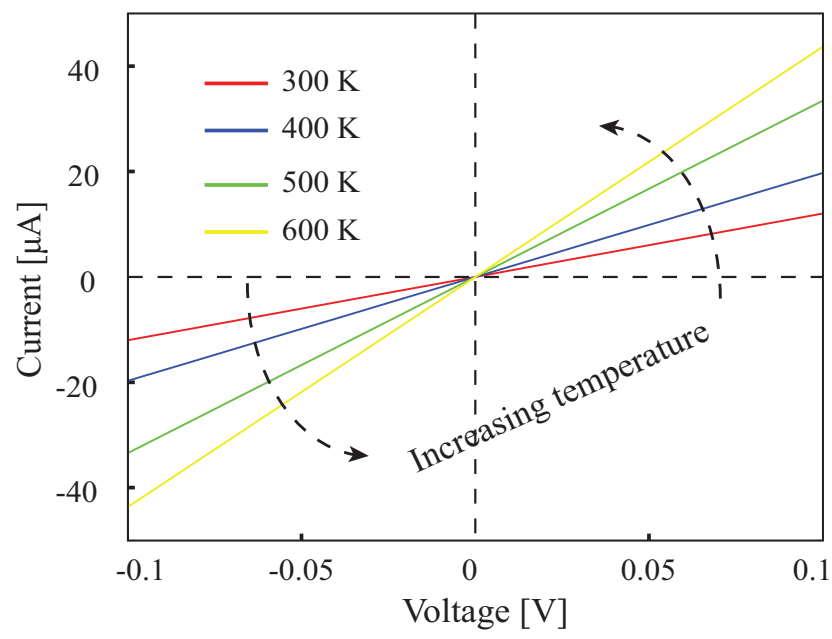

Fig. 3 The current-voltage (IV) characteristic of p-3C-SiC on $\mathrm{SiO}_{2}$ substrate measured at different temperatures. 
An experimental setup was established for the thermoresistive characterization of the $\mathrm{p}-3 \mathrm{C}-\mathrm{SiC}$ films $(\mathrm{ESI} \dagger)^{13}$. Figure 3 shows the typical current-voltage (I-V) curves of the p-3C-SiC film at various temperatures ranging from room temperature of $300 \mathrm{~K}$ to $600 \mathrm{~K}$. The applied voltage varied from $-0.1 \mathrm{~V}$ to $0.1 \mathrm{~V}$. The I-V curves show that a good contact between the aluminum electrodes and the p-type $3 \mathrm{C}-\mathrm{SiC}$ was maintained in the whole temperature range. The I-V data also indicate that the conduction of $\mathrm{SiC}$ is thermally activated, because impurities are ionized with increasing temperature. In addition, the thermoelectric effect of the Al-W junction can be neglected because the temperature distribution of the device is expected to be uniform. This assumption is experimentally supported by the fact that the linear I-V curves pass through the origin at elevated temperatures (Fig. 3, ESI $\dagger$ ).

Fig. 4(a) shows the resistance values derived from the I$\mathrm{V}$ data. The resistance decreases significantly with increasing temperature (e.g. up to $80 \%$ at $600 \mathrm{~K}$ ). As a result, the measured temperature coefficient of resistance (TCR) varies from $-2400 \mathrm{ppm} / \mathrm{K}$ to $-5500 \mathrm{ppm} / \mathrm{K}$, Fig. 4(b). This TCR is comparable to that of other thermal sensing materials such as platinum (3920 ppm/K).

The p-type 3C-SiC doped with a concentration of $5 \times$ $10^{18} \mathrm{~cm}^{-3}$ possesses sensitive ionization characteristics with increasing temperature, evident through the significant increase of its conductivity. We hypothesise that the free hole concentration $(n)$ increases with increasing temperature, and remains constant once the impurities are fully ionized. Therefore, the absolute TCR is large near room temperature and decreases with increasing temperature as a result of the decrease in the hole mobility. The temperature dependence of hole concentration in $\mathrm{p}-3 \mathrm{C}-\mathrm{SiC}$ can be expressed as ${ }^{31,32}$ :

$$
n \sim T^{3 / 2} \exp \left(-\frac{E_{a}}{k T}\right)
$$

where $E_{a}$ is the activation energy of the acceptor (hole), and $k$ is the Boltzmann constant. In addition, the hole mobility decreases with increasing temperature and can be simply determined as ${ }^{33-35}$ :

$$
\mu \sim T^{-\alpha}
$$

where $\alpha$ is an experimental constant. The resistivity ( $\rho$ ) of the $\mathrm{SiC}$ films can be determined from the hole concentration (Eq. 1) and its mobility (Eq. 2) using Eq. 3 as follows:

$$
\rho=\frac{1}{q \mu n} \sim T^{\alpha-3 / 2} \exp \left(\frac{E_{a}}{k T}\right)
$$

where $q$ is the electron charge. Deducing from Eq. (3), the relationship between the resistance change and the temperature can be written in the following form:

$$
\ln \left(\frac{R}{R_{0}}\right)=\left(\alpha-\frac{3}{2}\right) \ln \left(\frac{T}{T_{0}}\right)+E_{a}\left(\frac{1}{k T}-\frac{1}{k T_{0}}\right)
$$
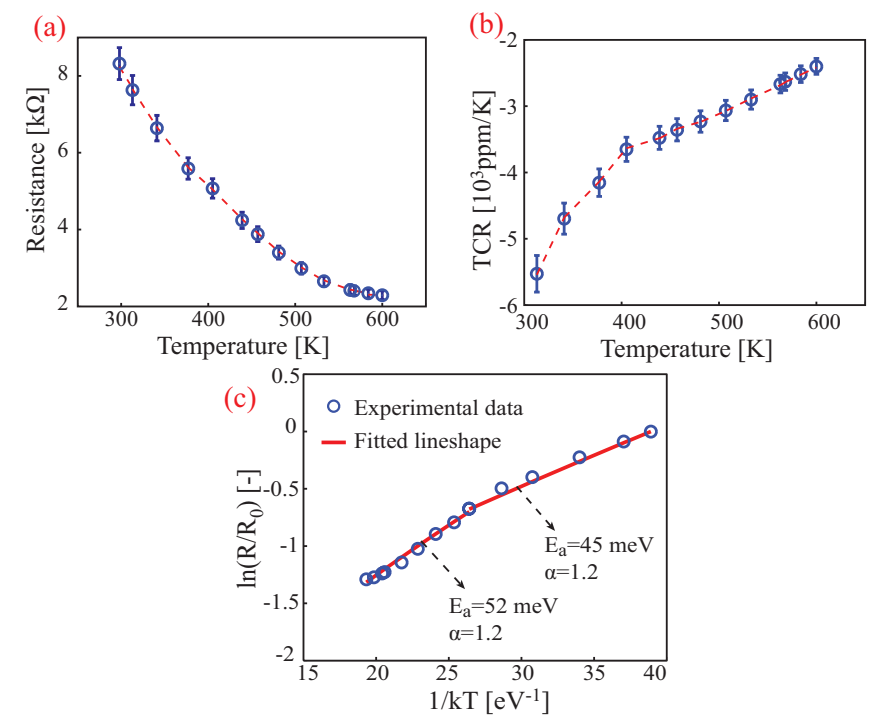

Fig. 4 Thermoresistive characteristics of the p-3C-SiC on $\mathrm{SiO}_{2}$ platform: (a) Electrical resistance versus temperature (Number of samples N=4); (b) Temperature coefficient of resistance (TCR) of the p-3C-SiC material; (c) Non-linear Arrhenius plot of the $\mathrm{p}-3 \mathrm{C}-\mathrm{SiC}$ thermoresistance and its fitting curves.

where $\mathrm{R}_{0}$ is the $\mathrm{SiC}$ resistance at the reference temperature $\mathrm{T}_{0}$. Figure 4(c) shows the non-linear Arrhenius plot of the p3C-SiC and its fitted curves based on Eq. 4. The hole mobility constant was found to be 1.2, and two activation energy thresholds of $45 \mathrm{meV}$ and $52 \mathrm{meV}$ were extracted, corresponding to temperature ranges of $300 \mathrm{~K}$ to approximately $450 \mathrm{~K}$ and 450 $\mathrm{K}$ to $600 \mathrm{~K}$, respectively. These low activation energy thresholds were found, which are due to the fact that the doped $\mathrm{SiC}$ film has a large hole concentration $\left(5 \times 10^{18} \mathrm{~cm}^{-3}\right)$. At this concentration, the impurities are partly ionized at room temperature. Thus, the Fermi level becomes closer to the valence band of SiC. In addition, as the low activation energy thresholds of $45 \mathrm{meV}$ and $52 \mathrm{meV}$ were found, it is likely that the holes from the acceptor levels require a small increase in thermal energy to be activated into the top edge of the valence band. Since the energy band gap of the 3C-SiC material is approximately $2.3 \mathrm{eV},{ }^{36}$ the calculated ratio of $2 \mathrm{E}_{a} / \mathrm{E}_{g}$ was much smaller than the utility, indicating that the Fermi level is deeply located in the lower region of the forbidden band. It is also important to note that the scattering mechanism cannot be neglected, since the phonon scattering $\mu \sim T^{-1.2}$ limits the decrease in the resistivity of the $\mathrm{SiC}$ film at high temperatures.

In conclusion, we investigated the thermoresistive properties of p-3C-SiC grown on Si substrate, peeled off by FIB, and subsequently transferred on to a glass substrate. We then studied the conduction mechanism of the $\mathrm{SiC}$ material and found two low activation energy thresholds of $45 \mathrm{meV}$ and $52 \mathrm{meV}$, as well as a temperature dependent mobility of $\mu \sim T^{-1.2}$. A negative and large TCR up to $-5500 \mathrm{ppm} / \mathrm{K}$ was also obtained, demonstrating the feasibility of using this material for 
thermal-based sensors working in high-temperature environments.

This work was performed in part at the Queensland node of the Australian National Fabrication Facility, a company established under the National Collaborative Research Infrastructure Strategy to provide nano and micro-fabrication facilities for Australia's researchers. This work has been partially supported by the Griffith University's New Researcher Grants and Australian Research Council grant LP150100153.

\section{References}

1 M. Mehregany, C. Zorman, N. Rajan, C. H. Wu, Proceedings of the IEEE, 1998, 86(8), 1594.

2 V. Cimalla, J. Pezoldt and O. Ambacher, J. Phys. D: Appl. Phys, 2007, 40, 6386.

3 H.P. Phan, D.V. Dao, K. Nakamura, S. Dimitrijev, and N.T. Nguyen, JMEMS, 2015, DOI 10.1109/JMEMS.2015.2470132.

4 H. P. Phan, D. V. Dao, L. Wang, T.Dinh, N. T. Nguyen, A. Qamar, P. Tanner, S. Dimitrijev and Y. Zhu, J. Mater. Chem. $C, 2015, \mathbf{3}(6), 1172$.

5 A. Qamar, P. Tanner, D. V. Dao, H. P. Phan, T. Dinh, Electron Device Letters, 2014, 35(12), 1293.

6 A. Qamar, D. V. Dao, P. Tanner, H. P. Phan, T. Dinh, and S. Dimitrijev, Applied Physics Express, 2015, 8(6), 061302.

7 L. Wang, S. Dimitrijev, J. Han, P. Tanner, A. Iacopi, and L. Hold, Journal of Crystal Growth, 2011, 329(1), 67.

8 H. P. Phan, D. V. Dao, P. Tanner, L. Wang, N. T. Nguyen, Y. Zhu, S. Dimitrijev, Appl. Phys. Lett., 2014, 104(11), 111905.

9 H. P. Phan, P. Tanner, D. V. Dao, L. Wang, N. T. Nguyen, Y. Zhu, S. Dimitrijev, Electron Device Lett., 2014, 35(3), 399.

10 S. Noh, J. Seo, and E. Lee, Trans. Electr. Electron. Mater, 2009, 10, 131.

11 X. Lin, S.Lin, Y. Xu, A. A. Hakro, T. Hasan, B. Zhang, and H. Chen, J. Mater. Chem. C, 2013, 1(11), 2131.

12 C. Lyons, A. Friedberger, W. Welser, G. Muller, G. Krotz, and R. Kassing, Proc. Micro Electro Mechanical Systems, $1998,356$.

13 T. Dinh, D. V. Dao, H. P. Phan, L. Wang, A. Qamar, N.T. Nguyen, P. Tanner, and M. Rybachuk, Appl. Phys. Express, 2015, 8, 061303.

14 C. Yan, J. Wang, and P. S. Lee, ACS nano, 2015, 9(2), 2130-2137.

15 T. Dinh, H. P. Phan, D. V. Dao, P. Woodfield, A. Qamar and N. T. Nguyen, J. Mater. Chem. C, 2015, 10.1039/C5TC01650A

16 N.T. Nguyen, IEEE Sensors J., 2005, 5, 1224-1234.
17 W. C. Lin, M. A. Burns, Analytical Methods, 2015, 7(9), 3981.

18 V. T. Dau, D. V. Dao, and S. Sugiyama, Smart Mater. and Struct., 2007, 16, 2308-2314.

19 D. V. Dao, V. T. Dau, T. Shiozawa, and S. Sugiyama. JMEMS, 2007, 16, 950-958.

20 V. T. Dau, D. V. Dao, T. Yamada, B. T. Tung, K. Hata and S. Sugiyama, Smart Mater. and Struct., 2010, 19(7), 075003.

21 J. T. W. Kuo, L. Yu, and E. Meng. Micromachines, 2012, 3, 550-573.

22 C. Dezauzier, N. Becourt, G. Arnaud, S. Contreras, J. L. Ponthenier, J. Camassel and C. Jaussaud, Sensor Actuat. APhys., 1995, 46(1), 71.

23 F. Mailly, A. Giani, R. Bonnot, P. Temple-Boyer, F. FascalDelannoy, A. Foucaran, and A. Boyer, Sensor Actuat. APhys., 2001, 94, 32-38.

24 L. Di Cioccio, F. Letertre, Y. Le Tiec, A. M. Papon, C. Jaussaud, and M. Bruel, Materials Science and Engineering: $B, 1997, \mathbf{4 6}(1), 349$.

25 Q. Y. Tong, U. Gosele, C. Yuan, A. J. Steckl, M. Reiche, Journal of The Electrochemical Society, 1995, 142(1), 232.

26 H. P. Phan, D. V. Dao, P. Tanner, L. Wang, N. T. Nguyen, Y. Zhu, and S. Dimitrijev, Applied Physics Letters, 2014, 104(11), 111905.

27 H. Yugami, S. Nakashima, A. Mitsuishi, A. Uemoto, M. Shigeta, K. Furukawa, and S. Nakajima, Journal of applied physics, 1987, 61(1), 354.

28 A. Qamar, H. P. Phan, D. V. Dao, P. Tanner, T. Dinh, L. Wang, and S. Dimitrijev, Electron Device Letters, 2015, 36(7), 708.

29 H. P. Phan, A. Qamar, D. V. Dao, T. Dinh, L. Wang, J. Han and N. T. Nguyen, RSC Advances, 2015, 5(69), 56377.

30 D. Xu, B. Xiong, G. Wu, Y. Wang, X. Sun and Y. Wang, J. Microelectromechanical Systems, 2012, 21(6), 1436.

31 S. O. Kasap, Semiconductor, Principles of Electronic Materials and Devices, New York, NY: McGraw-Hill, 2006, 373.

32 S. S. Li and W. R. Thurber, Solid-State Electronics, 1977, 20(7), 609.

33 S. O. Kasap, Electrical and thermal conduction in solids, Principles of Electronic Materials and Devices, New York, NY: McGraw-Hill, 2006, pp. 113.

34 M. Roschke and F. Schwierz, IEEE Transactions on Electron Devices, 2001, 48(7), 1442.

35 K. Sasaki, E. Sakuma, S. Misawa, S. Yoshida, and S. Gonda, Applied physics letters, 1984, 45(1), 72.

36 R. G. Humphreys, D. Bimberg and W. J. Choyke, Solid St. Commun., 1981, 39, 163. 

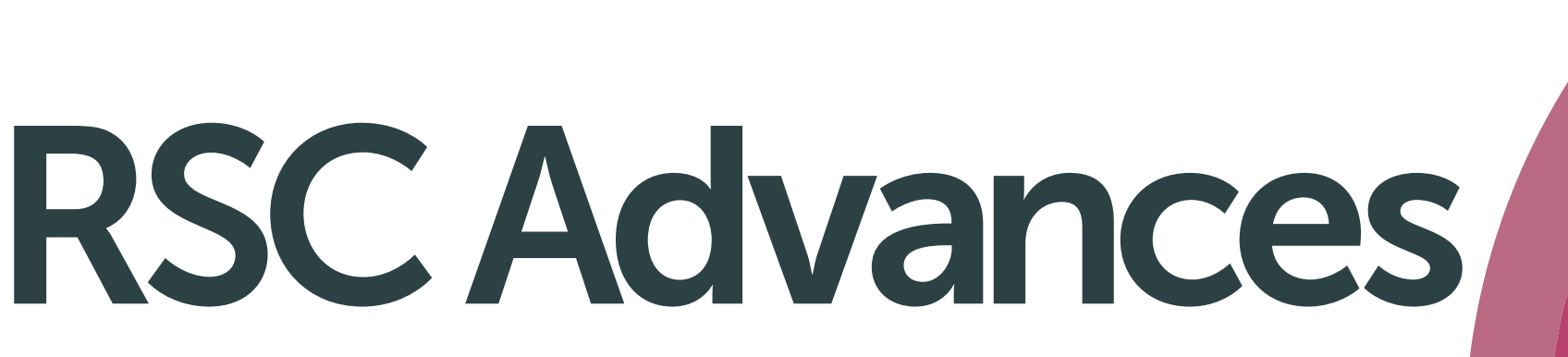

Volume1 Number1 Jan 2013 $\mid$ Pages 1-100

\section{RSC Advances}

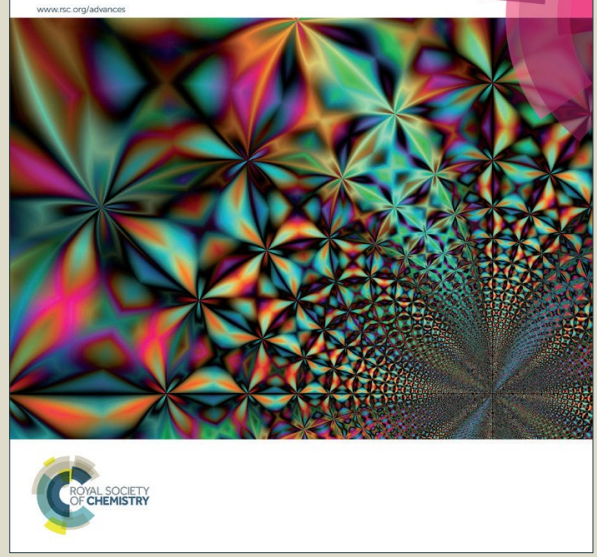

This is an Accepted Manuscript, which has been through the Royal Society of Chemistry peer review process and has been accepted for publication.

Accepted Manuscripts are published online shortly after acceptance, before technical editing, formatting and proof reading. Using this free service, authors can make their results available to the community, in citable form, before we publish the edited article. This Accepted Manuscript will be replaced by the edited, formatted and paginated article as soon as this is available.

You can find more information about Accepted Manuscripts in the Information for Authors.

Please note that technical editing may introduce minor changes to the text and/or graphics, which may alter content. The journal's standard Terms \& Conditions and the Ethical guidelines still apply. In no event shall the Royal Society of Chemistry be held responsible for any errors or omissions in this Accepted Manuscript or any consequences arising from the use of any information it contains. 